\title{
Assimilation of Antarctic velocity observations provides evidence for uncharted pinning points
}

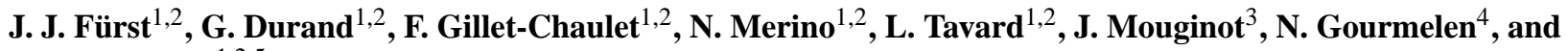 \\ O. Gagliardini ${ }^{1,2,5}$ \\ ${ }^{1}$ CNRS, Laboratoire de Glaciologie et Géophysique de l'Environnement (LGGE), Grenoble, France \\ ${ }^{2}$ Université Grenoble Alpes, LGGE, Grenoble, France \\ ${ }^{3}$ University of California, Department of Earth System Science, Irvine, USA \\ ${ }^{4}$ The University of Edinburgh, School of GeoSciences, Edinburgh, UK \\ ${ }^{5}$ Institut Universitaire de France, Paris, France \\ Correspondence to: J. J. Fürst (johannes.fuerst@lgge.obs.ujf-grenoble.fr)
}

Received: 16 February 2015 - Published in The Cryosphere Discuss.: 5 March 2015

Revised: 25 May 2015 - Accepted: 18 June 2015 - Published: 4 August 2015

\begin{abstract}
In ice flow modelling, the use of control methods to assimilate the dynamic and geometric state of an ice body has become common practice. These methods have primarily focussed on inverting for one of the two least known properties in glaciology, namely the basal friction coefficient or the ice viscosity parameter. Here, we present an approach to infer both properties simultaneously for the whole of the Antarctic ice sheet. After the assimilation, the root-meansquare deviation between modelled and observed surface velocities attains $8.7 \mathrm{~m} \mathrm{a}^{-1}$ for the entire domain, with a slightly higher value of $14.0 \mathrm{~m} \mathrm{a}^{-1}$ for the ice shelves. An exception in terms of the velocity mismatch is the Thwaites Glacier Ice Shelf, where the RMS value is almost $70 \mathrm{ma}^{-1}$. The reason is that the underlying Bedmap2 geometry ignores the presence of an ice rise, which exerts major control on the dynamics of the eastern part of the ice shelf. On these grounds, we suggest an approach to account for pinning points not included in Bedmap2 by locally allowing an optimisation of basal friction during the inversion. In this way, the velocity mismatch on the ice shelf of Thwaites Glacier is more than halved. A characteristic velocity mismatch pattern emerges for unaccounted pinning points close to the marine shelf front. This pattern is exploited to manually identify seven uncharted features around Antarctica that exert significant resistance to the shelf flow. Potential pinning points are detected on Fimbul, West, Shackleton, Nickerson and Venable ice shelves. As pinning points can provide substantial resistance to shelf flow, with considerable consequences if they
\end{abstract}

became ungrounded in the future, the model community is in need of detailed bathymetry there. Our data assimilation points to some of these dynamically important features not present in Bedmap2 and implicitly quantifies their relevance.

\section{Introduction}

More than $60 \%$ of the grounded parts of the Antarctic ice sheet extends into a distinct floating ice shelf (Fretwell et al., 2013). A minority of these shelves can be considered to be mostly unconfined, which implies that their influence on the upstream ice flow is limited (e.g. Schoof, 2007). The vast majority are however confined and exert control on the upstream ice flow and by extension on the ice discharge from the grounded ice sheet. Ice discharge is the flux over the grounding line (e.g. Shepherd et al., 2012; Depoorter et al., 2013; Rignot et al., 2013), which itself is the delineation of where the ice body starts to float on its way to the ice-sheet margin. Changes in ice discharge rates quantify the dynamic contribution of the ice sheet to sea level (Rignot et al., 2008), because it is there where the ice overburden is no longer supported by an underlying bed. As most shelves are well confined, a reduction or even a loss in the resistance provided by these confinements is expected to trigger an abrupt increase in ice discharge and thus in rates of sea-level contribution (Favier et al., 2012). 
An ice-shelf confinement can simply be an embayment formed either by promontories or by ridges with grounded ice protruding from the ice sheet. In such a setup, the shelf experiences high lateral resistance (Thomas, 1979). This resistance is directly identifiable from pronounced cross-flow gradients in the observed surface velocities. Other confinements are embedded within floating ice shelves and are thus disconnected from the hinterland. For these pinning points, the ice shelf locally runs aground and the bed contact provides friction at the basal interface. Pinning points often give rise to longitudinal resistance, i.e. a pressure acting on a plane perpendicular to the ice flow. Any form of resistance imposed on the membrane-like flow regime of an ice shelf is often referred to as buttressing (Hindmarsh, 2006; Schoof, 2007). In general, there are three distinct classes of pinning points (e.g. Armstrong et al., 1977; Thomas, 1979): ice rises, ice rumples and ephemeral ice rumples. Ice rises show a rather strong basal contact and they are characterised by a locally defined flow regime which is normally well expressed in the surface topography. For ice rumples, the contact is weaker and thus the flow regime is primarily determined non-locally by the dynamic state of the surrounding ice shelf. Ice rumples are called ephemeral if there is evidence that the weak bed contact is not permanent. Ocean tides, for instance, give rise to such intermittent contact. In any case, pinning points do not necessarily require a large horizontal extent to significantly alter the large-scale shelf flow.

When assimilating observations on the geometric and dynamic state of an ice sheet with a flow model, attention has to be paid to pinning points as their influence on the shelf dynamics can reach far. In glaciological modelling, data assimilation often takes the observed geometry for granted and tries to optimise unknown model parameters to minimise the mismatch to other observations (e.g. MacAyeal, 1993). For this purpose, inverse methods or control methods have been suggested that aim at minimising differences between observed and modelled surface velocities under a given geometry (MacAyeal, 1993). Based on Antarctic-wide compilations of ice geometry and surface velocities (Rignot et al., 2011b; Fretwell et al., 2013), Morlighem et al. (2013) and Arthern et al. (2015) have shown that inverse methods are feasible at the continental scale. Both studies use a state-of-the-art ice flow model to infer the largely unknown basal friction beneath the grounded part of the Antarctic ice sheet. They find that low friction is widespread and can indeed reach far inland along tributary glaciers and ice streams. Here, we want to pursue a similar approach to assimilate velocity observations but we aim at a better quantification and understanding of remaining velocity differences.

In principle, remaining velocity differences can arise from three main sources during the data assimilation. They can originate from the optimisation procedure, the ice flow model or the actual measurements. In the first case, the optimisation might suffer from a bad choice of the cost function or an ex- cessive regularisation term. Moreover, convergence has to be guaranteed. Second discrepancies can arise from the underlying flow model. This can imply that the model physics is not appropriate to describe the observed flow behaviour. In this case, the model might rely on approximations not suitable for a particular flow regime or might ignore essential processes. Another point is that the model resolution chosen has to be compatible with the observations. Finally, remaining discrepancies might be linked to the observational input. Measurements come with uncertainties, which intrinsically impedes their reproduction. In order to capture the spatial variability of observed surface velocities, the resolution of the geometry input has to be sufficiently fine. In large data compilations, any inconsistencies among different data sources or simple local incompleteness might also give reason to biases. In regions where fast changes are observed, acquisition dates of ice flow and geometry should be as contemporaneous as possible.

In this study, we apply control methods on the recent data sets for Antarctic-wide ice geometry and surface velocities (Sect. 2). The aim is to assess the origin of remaining differences between the observed and modelled velocities (Sect. 3). It is found that mismatches are most expressed on the ice shelves in areas where pinning points are missing in the Bedmap2 data set (Sect. 3.3.1). We suggest an approach to account for complementary information on grounding in the inversion (Sect. 3.3.2) and use a characteristic mismatch pattern to identify, to this day, uncharted pinning points (Sect. 3.3.3).

\section{Model description}

\subsection{Ice flow model}

Elmer/Ice is an open-source 3-D thermomechanically coupled ice flow model (Gagliardini and Zwinger, 2008; GilletChaulet et al., 2012; Gagliardini et al., 2013) and the glaciological extension of the Elmer finite element software developed at the Center for Science in Finland ( CSC-IT, http: //www.csc.fi/elmer/). It is an efficient, state-of-the-art tool to solve the full complexity of the underlying force balance equations.

As we put the focus on the floating parts of the ice sheet, a model variant is applied that solves the shallow-shelf approximation (SSA; e.g. MacAyeal, 1989). In this approximation, gravitational driving is balanced by basal friction and by an overall adjustment of the stress regime, which is communicated by gradients in membrane stresses (Hindmarsh, 2006). Basal friction is considered negligible for floating ice shelves. There, the membrane stress effect exclusively depends on the effective viscosity $\eta$ of the material. The effective viscosity comprises the non-linearity in the constitutive equation, which links the deviatoric stress field $\boldsymbol{\tau}$ to rates of 
strain or ice deformation.

$\eta=\frac{1}{2} \cdot B \cdot \varepsilon_{\mathrm{e}}^{(1-n) / n}$

Here, $\varepsilon_{\mathrm{e}}=\sqrt{\varepsilon_{i j} \cdot \varepsilon_{i j} / 2}$ is the second invariant of the strain rate tensor $\boldsymbol{\varepsilon}$. We assume isotropic material properties and a flow exponent of $n=3$. For shelf dynamics, $B$ is sometimes referred to as ice rigidity (e.g. Borstad et al., 2013; Larour et al., 2014). However, terms such as rigidity and stiffness are strictly associated with elastic deformation. As $B$ determines the readiness of the viscous material to deform under a given stress, $B$ is here referred to as the viscosity parameter (Van Der Veen, 1999). To facilitate readability, we will likewise refer to it as the ice viscosity, though this is only the case for linearity in the constitutive equation, i.e. a Newtonian fluid.

At the ice-bedrock interface, a Coulomb-like friction law is applied (Paterson, 1994):

$\boldsymbol{\tau}_{\mathrm{b}}=\beta^{2} \cdot \boldsymbol{v}_{\mathrm{b}}$,

where $\boldsymbol{\tau}_{\mathrm{b}}$ and $\boldsymbol{v}_{\mathrm{b}}$ are vectors tangential to the glacier base for basal shear stress and ice velocity respectively. $\beta^{2}$ denotes the positively defined basal friction coefficient.

\subsection{Mesh}

The analysis presented here will focus on ice shelves, ice streams and fast outlet glaciers. Anisotropic mesh adaptation allows us to refine the grid in these regions (Morlighem et al., 2010; Gillet-Chaulet et al., 2012). First we distinguish between floating and grounded parts of the ice sheet, for which the target resolutions are respectively 1.2 and $50 \mathrm{~km}$. The lower bound is imposed by computational limitations. For any location away from the grounding line, the final grid shows a nominal resolution close to these values. The decrease in resolution takes place upstream of the grounding line and spans a band of roughly $100 \mathrm{~km}$. In addition to this, the grid is refined in areas where flow magnitudes exceed $10 \mathrm{ma}^{-1}$. There, the refinement follows the Hessian matrix of the observed velocities (Morlighem et al., 2010; GilletChaulet et al., 2012). In this way, maximum resolution is ensured for both the floating fringes of Antarctica and the main tributaries.

\subsection{Control method}

On the basis of the SSA equations, we simultaneously infer basal friction $\beta^{2}$ and ice viscosity $B$ using control methods building on the approach described in Gillet-Chaulet et al. (2012) and Gagliardini et al. (2013). In contrast to their methodology, we conduct a dual inversion as introduced by Arthern and Gudmundsson (2010) and applied on Antarctic scales by Arthern et al. (2015). Additionally, we adjust the cost function and start from a physically based initial guess for the two inversion variables. Convergence of the optimisation is assumed to be reached after 950 iterations. Then, the cost function decrease saturates and the overall root-meansquare (RMS) mismatch compares to the error in the velocity observations (Joughin, 2002; Rignot et al., 2011b). Any further convergence is considered to entail overfitting.

The total cost function $J$ comprises the velocity mismatch and two regularisation terms.

$J=J_{0}+\lambda_{\beta^{2}} \cdot J_{\beta^{2}}^{\mathrm{reg}}+\lambda_{B} \cdot J_{B}^{\mathrm{reg}}$

The mismatch between modelled and observed velocities is comprised in the first cost term $J_{0}$. Here, we use the original form suggested in MacAyeal (1993) that accounts for differences in both horizontal velocity components. $J_{0}$ is a discrete sum evaluated at all data locations. During the inversion, we actually optimise multiplier fields $m_{B}$ of the form $B=m_{B}^{2} \cdot B_{\text {ini }}$ (also see Gillet-Chaulet et al., 2012). The applied regularisation in turn penalises first spatial derivatives in the respective multiplier fields $m_{\beta^{2}}$ and $m_{B}$. The two additional terms $J_{\beta^{2}}^{\text {reg }}$ and $J_{B}^{\text {reg }}$ are added to the total cost $J$. They improve the conditioning of the underlying problem by suppressing overfitting of the velocity observations.

Since there is an interdependence when inverting for two variables simultaneously, the inferred fields are dependent on the initial guess (Arthern and Gudmundsson, 2010). To guarantee that the inferred variables remain in a physical range, the initial fields have to be selected with care. The initial guess for $\beta^{2}$ is found by assuming that basal drag equals the local driving stress. From another inversion of basal friction on Antarctica (Morlighem et al., 2013), we know that over most of the ice sheet interior these two are nearly equal. There, the initialisation of $\beta^{2}$ is expected to strongly facilitate the convergence of our optimisation. In regions where the ice flow becomes channelised and the large-scale character of ice-sheet dynamics is violated, this initialisation is less appropriate.

The initial field for the ice viscosity parameter $B$ is calculated from an ice temperature reconstruction (Van Liefferinge and Pattyn, 2013). Ice-shelf temperatures are inferred from assuming a local balance of surface accumulation and basal melt, as described in Pattyn (2010). The 3-D temperature information is translated into an ice viscosity using a standard Arrhenius relation (Paterson, 1994). Viscosity values are thereafter vertically averaged. Underlying temperatures come, however, with a certain uncertainty of several degrees Celsius (van den Broeke, 2008; Pattyn, 2010; Van Liefferinge and Pattyn, 2013). To test whether the inversion is sensitive to the initial temperature-based (TB) guess, we employ two options to replace these values on the ice shelves following Borstad et al. (2013). Avoiding their formal usage of flow-line theory, $B$ is determined by equating the horizontal force exerted in flow direction by ice deformation (the latter known from strain rates) with the vertically integrated hydrostatic back pressure. Apart from a different choice for 
the direction (namely perpendicular to the grounding line), Eqs. (6) and (8) in Gudmundsson (2013) determine the two required pressure terms while $B$ becomes accessible using the model-specific constitutive equation (as Eq. 20). The new $B$ field is referred to as the hydrostatically balanced (HB) viscosity. In its original form, Borstad et al. (2013) exclusively used this $\mathrm{HB}$ viscosity where values are lower than the TB field. As this correction is motivated from identifying the state of ice damage on floating shelves, we refer to this initial $B$ field as the damage-corrected (DC) viscosity.

\subsection{Observational input}

\subsubsection{Ice sheet geometry}

The ice sheet geometry is based on the recent Bedmap2 data compilation, presented at $1 \mathrm{~km}$ resolution (Fretwell et al., 2013). The Bedmap2 thickness map is inferred from roughly 25 million measurements, with about $2.5 \%$ of crossover information. Analysis of all crossovers indicates that $50 \%$ of the measurement differences fall in a $5 \mathrm{~m}$ window around the median at $-1 \mathrm{~m}$. As data were collected over several decades, this agreement seems to justify the assumption that changes in the ice sheet geometry through time are comparably small with respect to the measurement uncertainty. However, the standard deviation in the crossover differences is stated with $50 \mathrm{~m}$, suggesting that a non-negligible number of data either come at higher measurement uncertainty, are biased by the mission-specific methodology or simply suffer from geometric changes over time. In the Amundsen Sea embayment, the upper ice surface was observed to have decreased a lot during the observational record (Pritchard et al., 2009, 2012). In the frontal area of Pine Island Glacier (PIG), a 2011 survey had to be excluded from Bedmap2, as thinning reached $40 \mathrm{~m}$ with respect to more extensive earlier surveys conducted in 2004/05 (Vaughan et al., 2006; Holt et al., 2006). Near the grounding line, the Bedmap2 geometry might be less reliable because of large uncertainties in firn density and thickness, violation of the flotation assumption and a data interpolation that aims at providing continuity across the grounding line (Griggs and Bamber, 2011; Fretwell et al., 2013; Depoorter et al., 2013).

The Bedmap2 surface elevation, bedrock elevation, ice thickness and a given mask, for whether ice is grounded or afloat, are interpolated onto the model grid. For the Antarctic ice shelves, flotation needs to be assured in the model. The reason is that otherwise a bias is introduced on the hydrostatic back pressure propagating into the inversion. In any prognostic application, the geometry would immediately be put afloat in the flow model. The most direct option is to locally adjust the density of the ice column according to flotation (case abbreviated with $\mathbb{D}$ ). This option has the advantage that no changes have to be applied to the Bedmap2 geometry product. If one accepts prior changes, three geometry fields of the Bedmap2 could be readjusted, i.e. the upper and lower ice-shelf surfaces and the ice thickness. Prescribing one of them, the other two follow from the standard model densities for sea water and ice respectively at 1028 and $917 \mathrm{~kg} \mathrm{~m}^{-3}$. The three options are thus the prescription of either the thickness $(\mathbb{T})$, the upper surface $(\mathbb{U})$ or the lower surface $(\mathbb{L})$ from observations. All these options were implemented under the condition that the ice base did not exceed the bedrock topography. Independent of these geometric changes, the original Bedmap2 mask is used to delineate the area where no basal friction is applied. For completeness, we want to present another, more physically based, approach to guarantee flotation, not pursued here. It relies on the sparse information on the firn density and firn thickness distribution over ice shelves (Khazendar et al., 2009, 2011). In this approach, the upper surface is a priori lowered on the basis of the assumed firn properties before inferring the ice thickness from hydrostatic equilibrium.

Following option $\mathbb{D}$, a spatially variable density field with a shelf average of $865 \mathrm{~kg} \mathrm{~m}^{-3}$ is obtained. The derived density field shows, however, areas in which values exceed the density of most compact marine ice $940 \mathrm{~kg} \mathrm{~m}^{-3}$ (e.g Craven et al., 2009) or fall below typical values for dense firn of $700 \mathrm{~kg} \mathrm{~m}^{-3}$. Either way, these values are beyond the physical range as they are representative for the entire ice column. The standard model density lies at $917 \mathrm{~kg} \mathrm{~m}^{-3}$ and is thus higher than the inferred average, which results in a general lowering of the surface elevation by $15 \mathrm{~m}$ for adjusting the geometry according to option $\mathbb{T}$. If the upper $(\mathbb{U})$ or lower surface $(\mathbb{L})$ is prescribed, the shelf thickness is either increased or decreased by comparable values.

\subsubsection{Surface velocities}

Information on the dynamic state of the entire Antarctic ice sheet was recently brought together and presented in a single database by Rignot et al. (2011b). Surface velocity magnitudes were inferred from synthetic aperture radar (SAR) imagery acquired between 1996 and 2009 with five different satellite-mounted sensors. The coverage of this velocity mosaic is almost complete and errors in the inferred flow field fall below $10 \mathrm{ma}^{-1}$ over most of Antarctica. We do not use the later released high-resolution data but base ourselves on the earlier product with a $900 \mathrm{~m}$ sample spacing, because the inversion is limited by the $1 \mathrm{~km}$ grid of the Bedmap2 geometry. The velocity observations are not interpolated onto the model grid, because the underlying finite element approach intrinsically allows us to compute the velocity solution at any location. During the minimisation of the cost function, differences between modelled and observed flow speeds are calculated at the data locations in the velocity mosaic.

\subsubsection{Complementary grounding line information}

As a complement to the Bedmap2 product, independent snapshot information on grounding line positions all around 
Antarctica between 1994 and 2009 from differential satellite SAR interferometry (dInSAR) was consulted (Rignot et al., 2011a). This complementary information is of particular interest where pinning points on ice shelves are missing in Bedmap2. Though already identified in 2001 (Rignot, 2001; Rignot et al., 2014), a large ice rise on the eastern ice shelf of Thwaites Glacier (TWG) does not appear in Bedmap2 due to a lack of bathymetry data in this region. The friction this ice rise exerts at the shelf base is well imprinted in the surface velocity field, as flow speeds there are extremely low. A delineation of this ice rise, as in Rignot et al. (2014), was available. Not as influential, but also missing in Bedmap2 and Rignot et al. (2011a), Bawden Ice Rise (BIR) is situated on the northeastern marine front of Larsen C (LC) Ice Shelf (Borstad et al., 2013). We manually delineated the BIR using ALOS/PALSAR imagery.

\section{Results}

In Sects. 3.1 and 3.2, results are exclusively based on the Bedmap2 geometry without consulting other sources of information. First, two technical choices on the regularisation (Sect. 3.1.1) and the parameter initialisation (Sect. 3.1.2) are presented. Thereafter, different options to impose flotation on the model geometry are assessed (Sect. 3.1.3). For this comparison, the well-studied LC shelf is chosen. Subsequently, we pursue an assessment of the velocity mismatch after the inversion (Sect. 3.2) for the whole of the ice sheet and individual ice shelves. As the bathymetry beneath ice shelves is widely unknown, the Bedmap2 geometry ignores many pinning points. Complementary information on grounded ice is used to locate these areas, which allows us to discern a characteristic pattern in the velocity mismatch (Sect. 3.3.1). We then assimilate this complementary information in our inversion by allowing a local optimisation of the friction coefficient (Sect. 3.3.2). In a final step, we identify other potential pinning points not included in the data sets at hand (Sect. 3.3.3).

\subsection{A priori decisions}

\subsubsection{Regularisation}

During the iterative optimisation of the cost function, its initial value is decreased by more than 3 orders of magnitude. This primarily reduces the mismatch between modelled and observed velocities (Fig. 1). The simultaneous inversion of two parameters seems sufficiently well conditioned, by the applied regularisation and the fact that on the ice shelves only one parameter, namely the viscosity parameter $B$, is inferred.

In order to retrieve an appropriate parameter combination for $\lambda_{\beta^{2}}$ and $\lambda_{B}$, we rely on the L curve method (e.g. Hansen, 1992; Jay-Allemand et al., 2011; Morlighem et al., 2013, and references therein). The L curve gives a means to find a tradeoff between fitting a target quantity while keeping a certain smoothness in the optimised variable. In our case, we define an L surface by quantifying the mismatch between observed and modelled velocities $J_{0}$ as a function of the two regularisation terms $J_{\beta^{2}}^{\text {reg }}$ and $J_{B}^{\text {reg }}$ (Fig. 2). Each position on this plot is associated with one parameter combination and the sampling is equally spaced in a logarithmic sense. The L surface allows the identification of an area in parameter space avoiding two extremes: either overfitting of the velocity observations or excessive regularisation that dominates the cost function $J$. The exact parameter choice depends on the later purpose of the inverted fields. As our interest is in the velocity mismatch, which is correlated to $J_{0}$, we choose the combination for which $J_{0}$ passes through a first local minimum when decreasing $\lambda_{\beta^{2}}$ and $\lambda_{B}$. This local minimum is attained for $\lambda_{\beta^{2}}=10^{3}$ and $\lambda_{B}=10^{3}$.

\subsubsection{Parameter initialisation}

As our later assessment will focus on the performance of the inversion on the ice shelves, the sensitivity of the inferred viscosity is assessed under three initial fields that differ only on the floating parts (Sect. 2.3). The final pattern and magnitude of the viscosity $B$ compare well, independent of the initially chosen fields. They result in similar RMS deviation values for single shelves and the entire ice sheet (Table 1). Locally, where the DC and the HB option prescribe a very low initial $B$ value, the inferred viscosity field remains low after the regularised inversion. In general, however, the inversion is robust under different initial fields. For the latter results, we choose the TB initialisation because it is readily implemented and has a physical meaning for floating and grounded ice.

After the inversion, the multiplier for the friction field $m_{\beta^{2}}$ is characterised by values close to unity for most of the ice sheet interior. Along regions of fast ice flow, however, the inversion finds very low values, as confirmed by an earlier inversion on the continental scale (Morlighem et al., 2013; Arthern et al., 2015). The multiplier field $m_{B}$ for the ice viscosity generally falls into the range of 0.1 and 10 . The low variability suggests that both initial fields are well chosen in view of this dual inversion.

\subsubsection{Geometry at flotation}

In general, any option for imposing flotation on the shelf geometry in the model results in lower ice viscosity from the inversion as compared to the unadjusted case (Fig. 3a and b). The reasoning depends on the details of how flotation is imposed. For case $\mathbb{D}$ the shelf density is lower, resulting in less gravitational forcing, which is compensated by a small viscosity decrease in order to balance the same hydrostatic back pressure. In case $\mathbb{T}$ the ice-shelf volume beneath sea level is higher than in the original Bedmap2 geometry, resulting in an increased hydrostatic back pressure, compensated by lowering $B$. When the bottom shelf surface is prescribed $\mathbb{L}$, the 


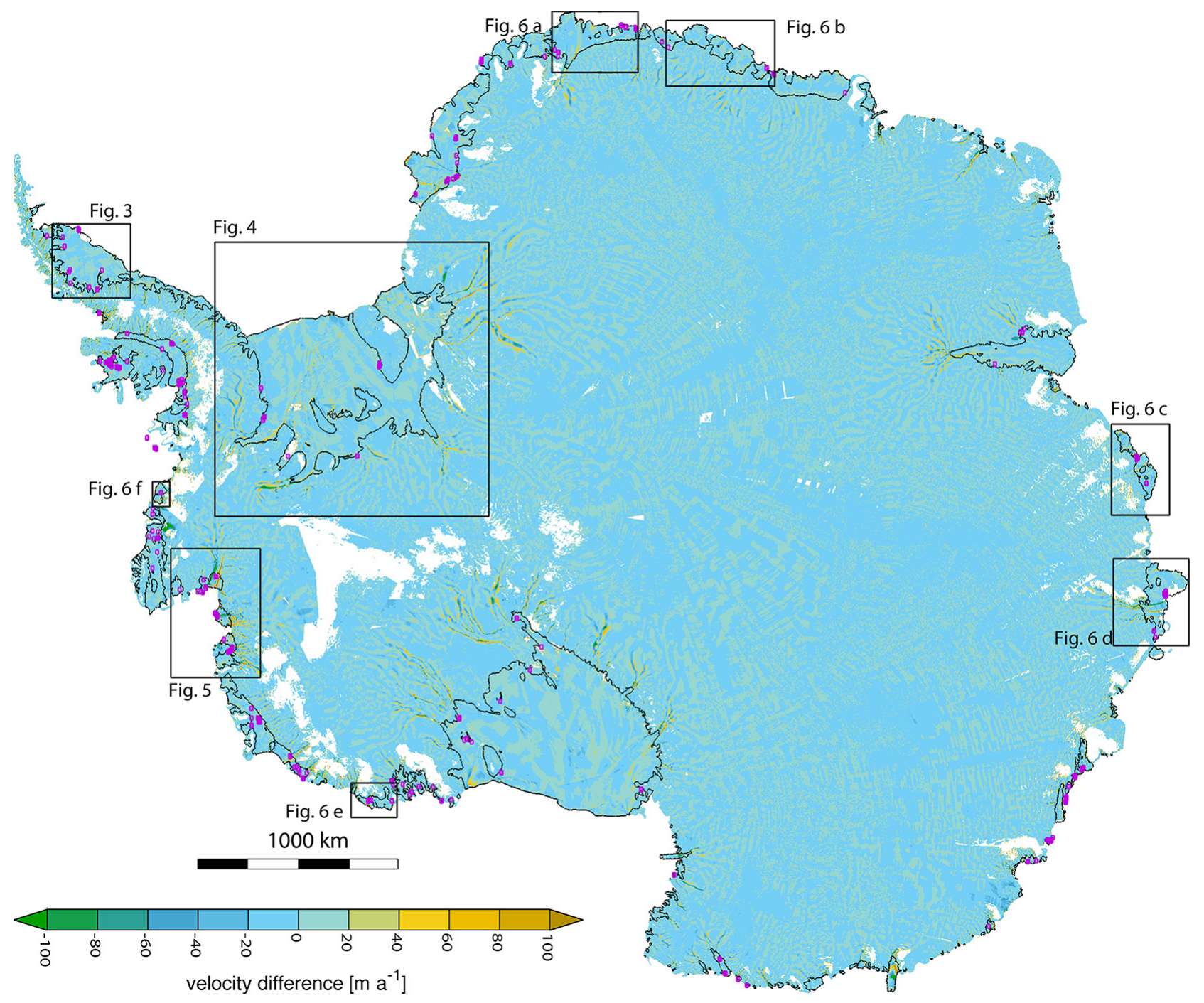

Figure 1. Difference of ice velocity magnitudes (simulated minus observed) over the Antarctic ice sheet. The result is based on the $\mathbb{T}$ geometry accounting for complementary information on pinning points. White areas over ice-covered areas indicate regions without velocity information. Pink squares indicate observed grounding line locations not included in Bedmap2 and further away than $5 \mathrm{~km}$ from grounded areas in Bedmap2 (PIN5). The black contour line delineates the floating shelves. Black rectangles indicate locations of insets.

back pressure is the same as for the original Bedmap2 data set. However, the shelf thickness and with it the driving stress are reduced, compensated in our inversion by a decrease in the viscosity parameter. The last case $\mathbb{U}$ is a combination of increasing both the driving stress and the back pressure simultaneously by thickening the shelf ice. As this results in the lowest $B$ values, the influence of the increased water back pressure seems dominant. In cases $\mathbb{T}$ and $\mathbb{L}$, the pursued adaptations of the shelf geometry also result in steeper surface gradients. Their influence seems secondary compared to the simultaneous effect from increasing back pressure by surface lowering in $\mathbb{T}$ or decreasing driving stress by thinning in $\mathbb{L}$.
Judging from the RMS deviation between observed and modelled surface velocities (Table 1), the choice on how to impose flotation affects the performance of the inversion. RMS values for the entire ice sheet indicate that the $\mathbb{L}$ geometry is least preferable. The other options show more comparable RMS values. The best agreement with observations is obtained with the unadjusted Bedmap2 geometry without and with the density corrections $(\mathbb{D})$. This good agreement is confirmed on the floating and grounded parts separately as well as on the level of individual ice shelves. For a further assessment, we consult the inferred viscosity parameter $B$. An average viscosity value for $L C$ is $0.48 \mathrm{MPa}^{1 / 3}$ for the unadjusted Bedmap2 geometry without density corrections. In this case, $B$ is biased towards high values as the geometry is not in balance with the flotation criterion in the 
Table 1. RMS deviation between simulated and observed velocity components for different regions. For the inversion, different option to ensure flotation on the ice shelves are assessed. As a reference, the input geometry is kept while assuming a constant ice density (Bedmap2). A second option is to locally adjust the density field on the ice shelves according to flotation $(\mathbb{D})$. Otherwise, an a priori adjustment of the geometry is necessary, keeping either the upper surface $(\mathbb{U})$, the lower surface $(\mathbb{L})$ or the thickness of the ice shelves $(\mathbb{T})$ from Bedmap2. For initialising the viscosity parameter on the shelves, three options are assessed based on inferred ice temperatures (TB), a local hydrostatic balance (HB) or a compromise of both used to identify damaged ice (DC). Complementary information on pinning points (Sect. 2.4.3) is accounted for in the inversion dependent on their distance from the Bedmap2 grounding line. Data are included if the distance is larger than either 1,5 or $10 \mathrm{~km}$, referred to as setup PIN1, PIN5 and PIN10 respectively.

\begin{tabular}{|c|c|c|c|c|c|c|c|c|c|c|}
\hline $\begin{array}{l}\text { Ice geometry } \\
\text { Initial viscosity }\end{array}$ & $\begin{array}{r}\text { Bedmap2 } \\
\mathrm{TB}\end{array}$ & $\begin{array}{r}\mathbb{D} \text { shelf } \\
\text { TB }\end{array}$ & $\begin{array}{r}\mathbb{U} \text { shelf } \\
\mathrm{TB}\end{array}$ & $\begin{array}{r}\mathbb{L} \text { shelf } \\
\text { TB }\end{array}$ & $\begin{array}{r}\mathbb{T} \text { shelf } \\
\text { TB }\end{array}$ & $\begin{array}{r}\mathbb{T} \text { shelf } \\
\text { DC }\end{array}$ & $\begin{array}{r}\mathbb{T} \text { shelf } \\
\text { HB }\end{array}$ & $\begin{array}{r}\text { PIN1 } \\
\text { TB }\end{array}$ & $\begin{array}{r}\text { PIN5 } \\
\text { TB }\end{array}$ & $\begin{array}{r}\text { PIN10 } \\
\text { TB }\end{array}$ \\
\hline Ross Ice Shelf & 9.3 & 8.9 & 12.4 & 14.0 & 10.6 & 10.5 & 10.4 & 10.3 & 10.0 & 10.3 \\
\hline Filchner-Ronne Ice Shelf & 11.6 & 11.8 & 14.9 & 18.4 & 14.0 & 13.9 & 13.8 & 13.7 & 13.5 & 13.8 \\
\hline Brunt/Stancomb-Wills Ice Shelf & 16.0 & 15.8 & 18.4 & 19.3 & 16.4 & 16.1 & 16.2 & 15.9 & 15.7 & 16.1 \\
\hline Shackleton Ice Shelf & 24.0 & 26.8 & 30.9 & 32.8 & 27.6 & 27.2 & 27.2 & 22.4 & 23.1 & 22.9 \\
\hline Amery Ice Shelf & 7.3 & 7.2 & 9.7 & 29.2 & 9.3 & 9.1 & 9.1 & 9.0 & 8.7 & 9.1 \\
\hline Larsen C & 9.5 & 9.4 & 11.6 & 12.1 & 10.6 & 10.5 & 10.4 & 9.5 & 9.4 & 9.7 \\
\hline Dotson Ice Shelf & 24.3 & 23.3 & 30.3 & 24.9 & 27.4 & 27.1 & 27.0 & 26.8 & 26.1 & 26.8 \\
\hline Crosson Ice Shelf & 15.8 & 15.5 & 19.0 & 24.9 & 17.9 & 17.7 & 17.5 & 17.4 & 17.0 & 17.4 \\
\hline Thwaites Glacier shelf & 57.9 & 57.5 & 85.7 & 76.2 & 67.8 & 68.1 & 66.0 & 28.9 & 31.1 & 29.3 \\
\hline Pine Island Glacier shelf & 31.4 & 30.9 & 37.3 & 67.2 & 34.0 & 33.6 & 33.6 & 33.4 & 32.9 & 33.5 \\
\hline Grounded part & 7.6 & 7.6 & 8.0 & 24.0 & 7.9 & 7.8 & 7.8 & 7.8 & 7.8 & 7.9 \\
\hline Floating part & 12.8 & 12.9 & 16.6 & 20.6 & 15.2 & 14.9 & 14.8 & 14.2 & 14.0 & 14.3 \\
\hline Antarctica & 8.4 & 8.4 & 9.5 & 23.7 & 9.1 & 9.0 & 9.0 & 8.8 & 8.7 & 8.9 \\
\hline
\end{tabular}

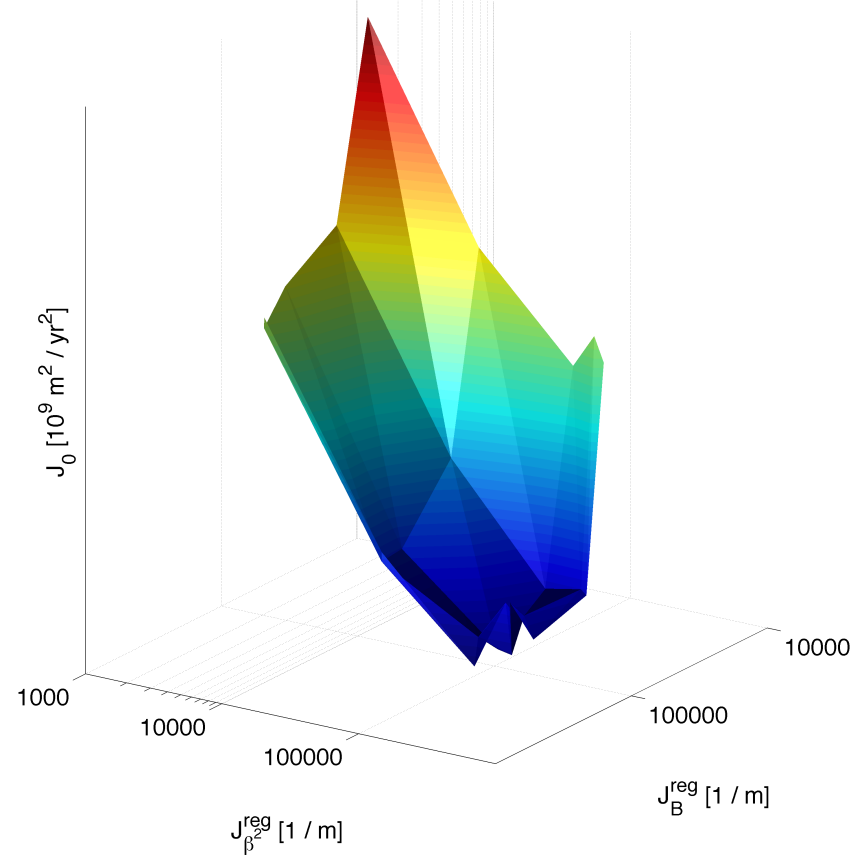

Figure 2. L surface obtained for the simultaneous optimisation of two variables as a function of the respective regularisation terms. model (Fig. 3a). The four options to guarantee flotation, $\mathbb{D}$, $\mathbb{U}, \mathbb{T}$ and $\mathbb{L}$, result in average ice-shelf viscosities of 0.46 , $0.42,0.37$ and $0.31 \mathrm{MPaa}^{1 / 3}$ respectively. As compared to the un-adjusted case, all shelf-average values are reduced but no preference can be given to either case. Jansen et al. (2010) forwarded an optimal value of $0.44 \mathrm{MPaa}^{1 / 3}$ when minimising the velocity mismatch with a uniform viscosity parameter. This value is, on view, confirmed by another inversion study on Larsen C (Khazendar et al., 2011). Also in terms of the velocity RMS deviation, the $\mathbb{D}, \mathbb{U}$ and $\mathbb{T}$ options result in similar values. A decision can therefore not been taken considering only a single quantity.

The $\mathbb{D}$ option performs best in terms of RMS deviation and the resultant viscosity average compares well with other studies. However, issues arise for initialisation to prognostic modelling. Forward modelling is faced with advecting this density field while the underlying flow model comprises no processes that would cause spatial variability in the first place. The $\mathbb{U}$ geometry would be a good compromise in terms of RMS and viscosity average, yet the general increase of the ice-shelf thickness lacks a physical justification and violates the bathymetric information in places. From the remaining two options, the $\mathbb{L}$ option clearly performs worse in terms of RMS and shows the lowest viscosity average. Option $\mathbb{T}$ remains and has the advantage that ice thickness and thus ice volume is preserved from Bedmap2. The thickness is also the quantity which has originally been inferred on a physical basis for the Bedmap2 product Griggs and Bamber (2011); Fretwell et al. (2013). 

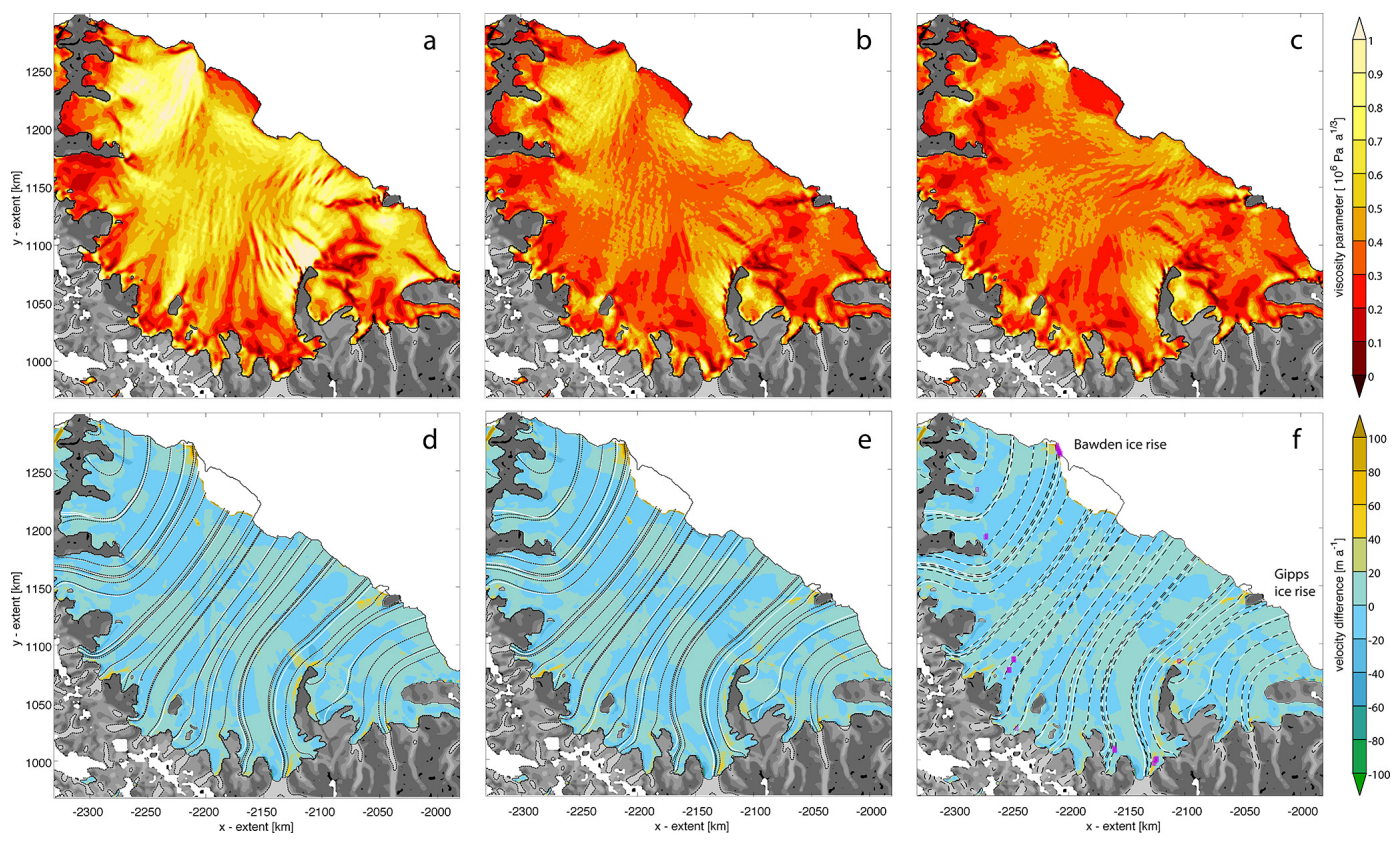

Figure 3. Ice viscosity parameter (a-c) as inferred by the control method for the Larsen C Ice Shelf. Velocity difference (d-f) as in Fig. 1. Panels (a, d) show results based on the actual Bedmap2 geometry, while panels (b, e) show results after flotation is guaranteed using the $\mathbb{T}$ method. Inversion results on Larsen $\mathrm{C}$ for the $\mathbb{T}$ geometry accounting for friction beneath pinning points not included in Bedmap2 (c, f). Grey shading indicates observed velocity magnitude on grounded parts of the ice sheet. The Bedmap 2 shelf extent is indicated by a black contour line. On the shelf, black dashed and white lines indicate observed and modelled streamlines respectively. The black dashed line on the grounded areas gives the $100 \mathrm{ma}^{-1}$ isoline of the observed surface velocities. Locations of pinning points (PIN5) not in Bedmap2 are indicated with pink squares in panel (e).

\subsection{General performance}

In general, the inferred velocity field is in good agreement with observations (Fig. 1). The RMS differences between observed and modelled velocities reaches $8.7 \mathrm{ma}^{-1}$ for the whole of the Antarctic ice sheet (Table 1). Remaining discrepancies are either spatially confined or, if widespread, small in magnitude. A similar inversion for the whole of Antarctica shows a saturation of the bulk RMS deviation at $\sim 40 \mathrm{ma}^{-1}$ (Arthern et al., 2015). As they constrain the inversion not only by observations on surface velocities but also on accumulation rates and surface elevation changes, it is natural that the velocity RMS deviation is more reduced for our inversion. Here we did not follow their suggestions, as we do not want to initialise the flow model for transient simulations. The aim is to identify locations where the model is not able to reproduce observed ice flow.

The velocity mismatch on the grounded part of the ice sheet is smaller than on the floating parts, with RMS values of respectively 7.9 and $15.2 \mathrm{ma}^{-1}$ (Table 1). In large parts of the ice sheet interior, differences become very small (Fig. 1), justifying the choice for a coarse grid. However, the coarse resolution becomes insufficient for some channelised flow features. The velocity observations come at $900 \mathrm{~m}$ sample spacing and they are directly used in the optimisation. Therefore, a general mismatch pattern emerges for such chan- nelised flow: underestimation of observed velocities in the centre of these channels and overestimation of the lateral flow speeds. It is also apparent that where these channelised features approach the grounding line, the mismatch decreases and often vanishes as a direct consequence of the increasing resolution.

The Filchner-Ronne (FR) Ice Shelf is the second largest distinct floating unit of Antarctica. In an attempt to determine the complex rheology of the larger Ronne section of this shelf, Larour et al. (2005) used a similar inversion technique to determine $B$. Having put the shelf geometry afloat, they find values that vary between 0.3 and $0.9 \mathrm{MPa}^{1 / 3}$, confirming the range found here (Fig. 4). We also find soft ice in the elongated shear bands at both lateral shelf margins. With the increasing knowledge on ice velocities, our inversion is able to provide a viscosity map much richer in small-scale features. Turning towards differences between observed and modelled velocities, the early study reported an average mismatch of $50 \mathrm{~m} \mathrm{a}^{-1}$. Here, we find a RMS value of $15 \mathrm{ma}^{-1}$ for the entire FR Ice Shelf. Though this might suggest a threefold reduction, a direct comparison is impeded because the input geometry and velocity observations differ.

After the disintegration of Larsen B in 2002 (MacAyeal et al., 2003), many studies were directed towards assessing the dynamic conditions preceding this event or monitoring 

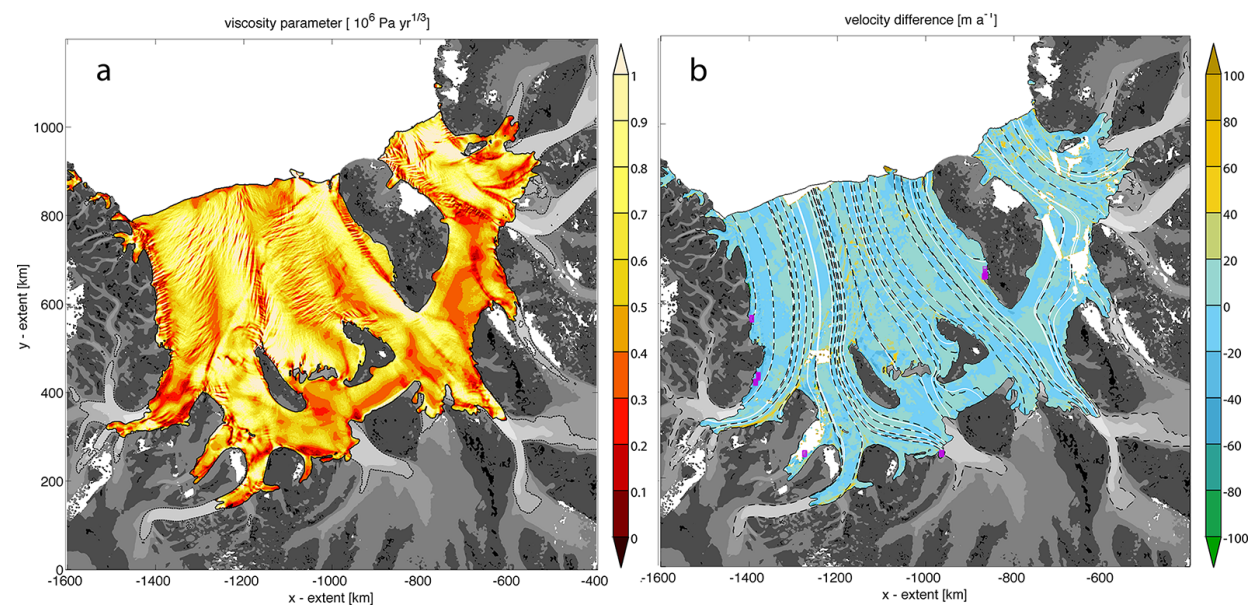

Figure 4. Ice viscosity parameter (a) and the difference between simulated and observed ice velocity magnitudes (b) on Filchner-Ronne Ice Shelf (as in Fig. 1). Shading and contour lines as in Fig. 3. Results are based on the $\mathbb{T}$ geometry without complementary information on pinning points. White areas indicate regions without velocity information.

the consequences for the tributary glaciers (Scambos et al., 2004; Vieli et al., 2006, 2007; Khazendar et al., 2007; Rott et al., 2011; Berthier et al., 2012). In addition, the LC Ice Shelf received some attention, being the next ice shelf in line just south of Larsen B (Jansen et al., 2010; Khazendar et al., 2011; Borstad et al., 2013; Kulessa et al., 2014). Prescribing a constant viscosity for the entire shelf, Jansen et al. (2010) succeed in reproducing the general pattern and magnitude of the velocity field. The match is convincing in the central part of the ice sheet, and a general tendency to underestimate observed velocities becomes only apparent in the southern parts of the shelf. As the viscosity parameter is spatially optimised, our inversion is free of such a regional bias (Fig. 3e). In fact, regions where ice velocities are either overor underestimated cover a similar area with 59 and $42 \%$ of the total ice-shelf surface respectively. In addition, the bulk RMS deviation is $9.4 \mathrm{~m} \mathrm{a}^{-1}$ and thus lies lower than the average mismatch for all Antarctic shelves (Table 1). In a more recent study, the LC viscosity parameter was inferred with the aim to identify regions of damaged ice (Khazendar et al., 2011; Borstad et al., 2013). In general, comparable $B$ fields are obtained (Fig. 3b). On Brunt/Stancomb-Wills Ice Shelf, inferred viscosity values are also comparable to a recent regional model study (Larour et al., 2014).

Highest surface velocities beyond $3000 \mathrm{ma}^{-1}$ are observed in the Amundsen Sea sector (ASS) and more specifically for PIG and TWG. For the central part of the PIG Ice Shelf, differences between simulated and observed flow velocities are efficiently reduced (Fig. 5). However, for the lateral shear margins, the mismatch exceeds $100 \mathrm{ma}^{-1}$, with different sign on each side of the fast-flow unit of the ice shelf. As this alternating pattern is identified for several other fast outlet glacier all around Antarctica, it is symptomatic and might indicate resolution issues, a regional under-convergence or a systematic minimum in the cost function for such setups. Another reason might be that the flow model is limited by the assumption of a continuous material, which might be violated in these areas of high crevassing. Turning to the ice viscosity, the inferred map shows two bands of very low values along these shear margins (not shown). Using a similar approach, Joughin et al. (2010) inverted comparable zones of weak ice in these areas.

On the ice shelf of TWG, a strong across-flow gradient in surface velocities is observed. Despite this gradient, our inversion finds no pronounced band of low viscosity. However, we infer untypically high viscosity $B$ for the central eastern part of the ice shelf, where values readily exceed $2.00 \mathrm{MPa} \mathrm{a}^{1 / 3}$. In addition, the $\sim 80 \mathrm{ma}^{-1}$ shelf-wide RMS velocity deviation is exceptionally elevated, with highest differences in this eastern region. At the source of these extreme values is a unconsidered contact between the bottom ice surface and the bathymetry (Sect. 2.4.3).

\subsection{Pinning point locations}

\subsubsection{Characteristic Bedmap2-based mismatch pattern}

The presented inversion is capable of adequately reproducing observed ice velocities for the majority of ice sheet. Pronounced remaining differences are spatially very confined and some features were attributed to a lack in model physics or coarse model resolution (Sect. 3.2). For floating ice away from the grounding line, the SSA is an appropriate description for ice dynamics. There, remaining differences between modelled and observed velocities likely arise from observational inconsistencies. In this section, we will characterise a prominent pattern in the velocity mismatch where Bedmap2 ignores the presence of pinning points known from complementary information (Sect. 2.4.3). 


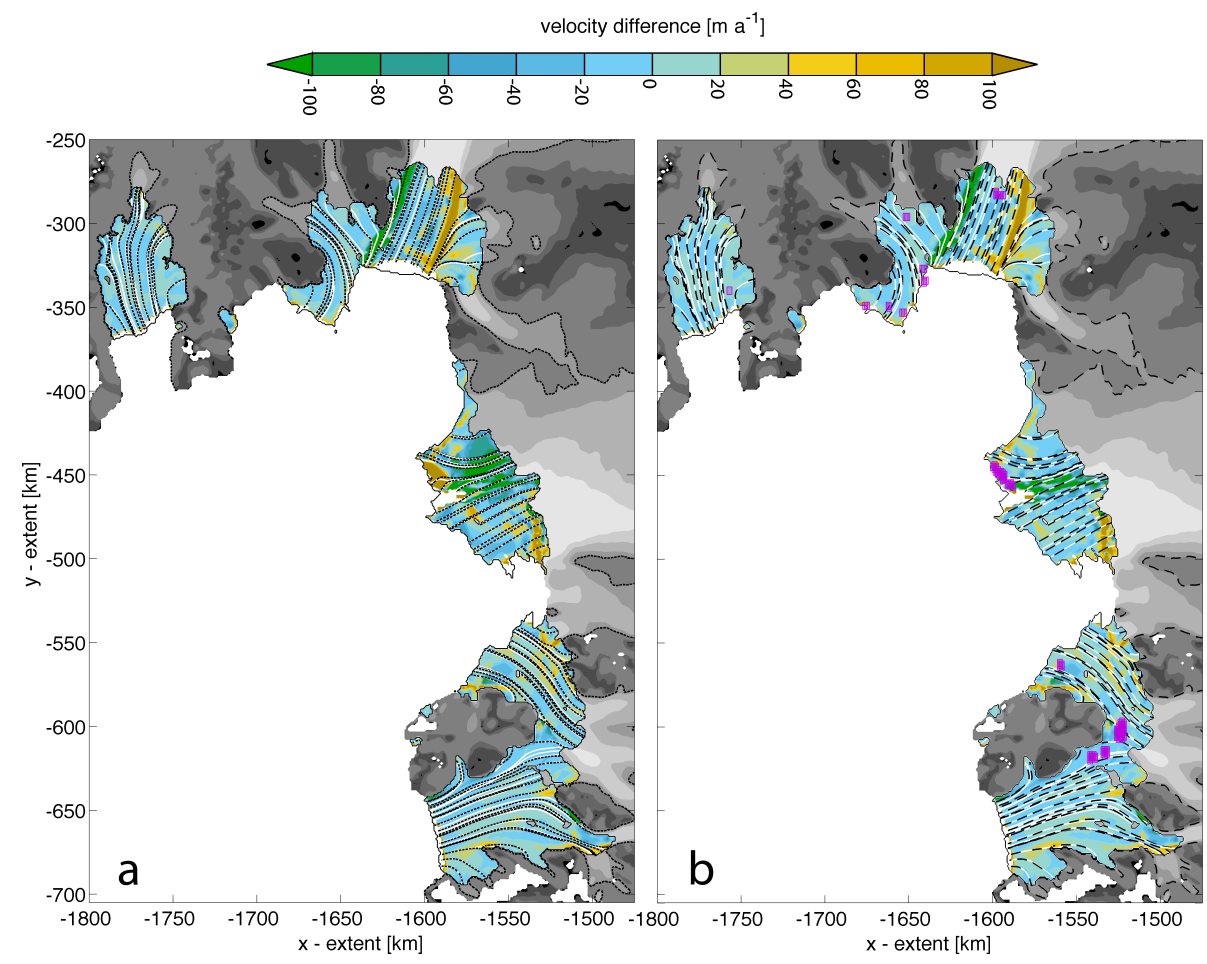

Figure 5. Velocity differences as in Fig. 4 for the ice shelves in the Amundsen Sea embayment. Results are based on the $\mathbb{T}$ geometry for the cases that complementary information on pinning points (pink rectangles, PIN5) is not accounted for (a) or accounted for (b) in the inversion. Shading, contour lines and markers as in Fig. 3.

It is obvious from surface velocity observations that the eastern ice shelf of TWG moves at much lower rates than the western parts. Towards the ice margin, observed flow magnitudes decrease significantly and the flow directions are deviated zonally. Flow resistance there arises from an ice rise near the marine shelf front (Rignot, 2001; Rignot et al., 2014). Since this ice rise is absent in Bedmap2, it gives an explanation for the high RMS deviation between observed and modelled surface velocities on this shelf (Table 1, Fig. 5). Nowhere else on Antarctica do we find widespread and high differences largely exceeding $100 \mathrm{ma}^{-1}$. Near the ice-shelf front, velocities are overestimated, while upstream of this narrow zone, inferred velocities are too low. As observed and modelled velocities cannot be conciliated, we consider that this ice rise has an important influence on ice dynamics of the entire eastern ice shelf and the upstream grounded ice flow. For other, less influential, pinning points not included in Bedmap2, we expect a much less pronounced mismatch pattern.

For the BIR on the northern part of the LC ice shelf, Bedmap2 shows no contact between the ice and the bathymetry (Fig. 3). Similar to the TWG setup, this pinning point is located close to the marine ice front. As basal friction there is kept zero during our inversion, the model overestimated ice velocities in its vicinity by more than $100 \mathrm{ma}^{-1}$. The spatial extent of this velocity mismatch reaches some
$50 \mathrm{~km}$ upstream. Further upstream, no distinct pattern for underestimation emerges. In this context, it is striking that the effect on the viscosity parameter $B$ reaches much further upstream. This might suggest that pinning points could be identified more directly from $B$. For the whole of Antarctica; however, we find that elevated viscosity values, as found in this region on LC, are not necessarily associated with pinning points but rather point to meteoric origins and little shearing of this ice. Overestimated flow speeds are found to be characteristic for pinning points absent in Bedmap2. For instance, near the McDonald Ice Rumples on Brunt/Stancomb-Wills Ice Shelf, the mismatch also exceeds $100 \mathrm{~m} \mathrm{a}^{-1}$ near the iceshelf front (Fig. 1). Magnitudes and pattern of this characteristic mismatch near unaccounted pinning points are comparable for all options on how to impose flotation. This can partly be inferred from the comparison of different geometry choices on Larsen $\mathrm{C}$ near Bawden Ice Rise (Fig. 3a-c).

Away from the close vicinity of the ice-sheet grounding line, the majority of the pinning points identified in Rignot et al. (2011a) are located near the shelf fronts (Fig. 1). However, there are many pinning points away from the marine fronts. For these points, we generally find that the remaining velocity mismatch is comparable to or falls below typical shelf RMS values (Figs. 3, 5, 6 and Table 1). Therefore, it is difficult to discern these features from the mismatch map. This indicates that either they are not as decisive for shelf dy- 

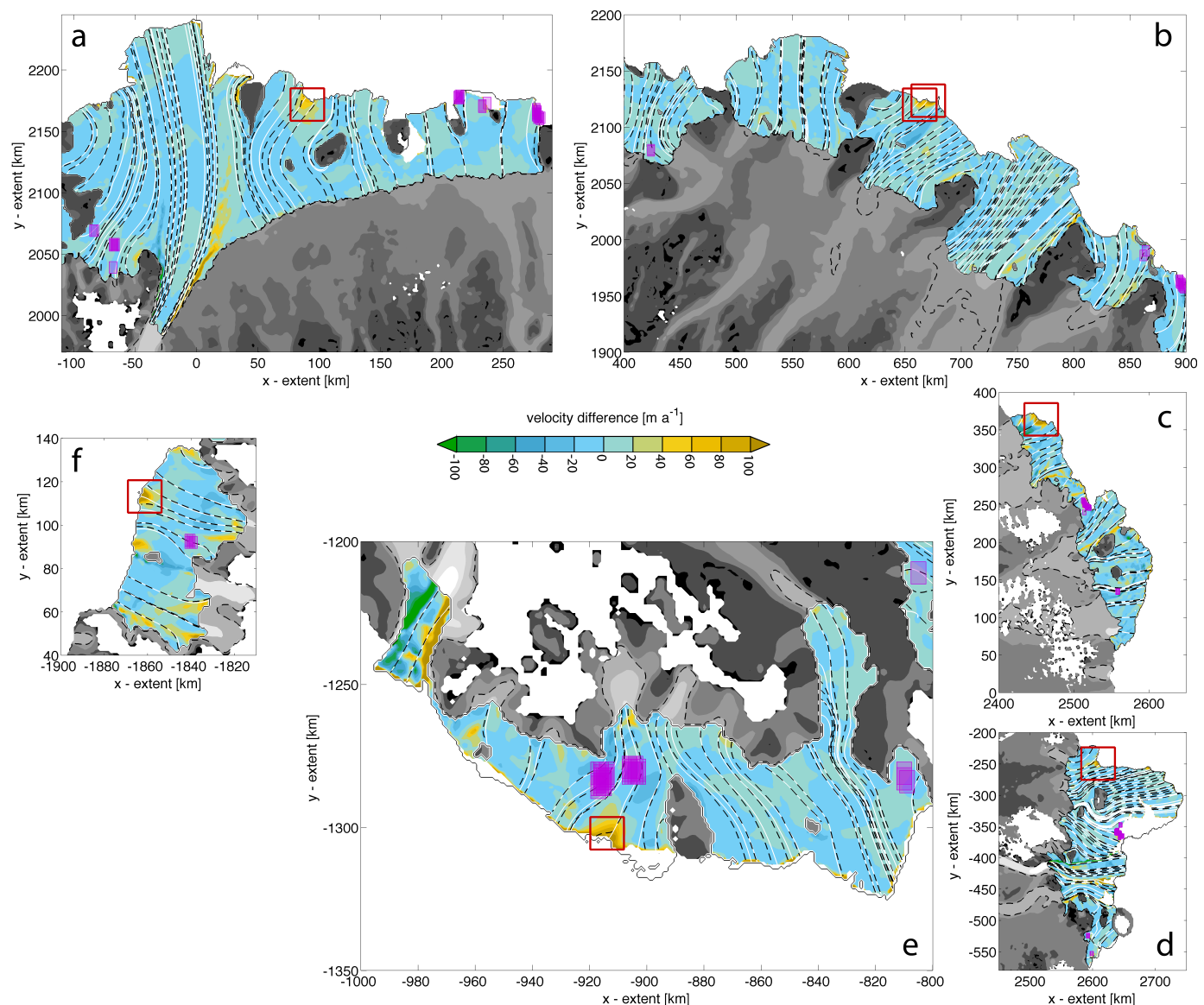

Figure 6. Velocity differences as in Fig. 4 for different ice shelves around Antarctica: Fimbul (a), Mushketov (b), West (c), Shackleton (d), Nickerson (e) and Venable (f). Results are based on the $\mathbb{T}$ geometry when accounting for complementary information on pinning points (PIN5) in the inversion. Shading, contour lines and markers as in Fig. 3. Dark red squares give the positions of the seven potential pinning points identified in this study (Table 2).

namics or our flow model can account for their effect in a different way. Further inland, shelf ice generally experiences more resistance; thus ice motion is slower and any model mismatch will be less expressed. It is also more likely that multiple sources provide resistance to a certain location on the ice shelf. Consequently, this superposition gives the inversion a possibility to conceal a missing pinning point by adjusting the weighting of various resistance sources via the viscosity parameter.

\subsubsection{Accounting for complementary information}

In this section, the Bedmap2 product is supplemented using complementary information on the location of shelf pinning from various sources (Sect. 2.4.3). These sources hold the location but not the bathymetry of these pinning points. These locations are stored in a mask which allows a local optimisation of the basal friction coefficient, even though Bedmap2 shows floating ice.

The dInSAR data from Rignot et al. (2011a) hold accurate pinning point locations with a spatial spacing below the
Bedmap2 grid spacing. The Bedmap2 geometry was primarily gridded and processed on $5 \mathrm{~km}$ resolution and only rendered at $1 \mathrm{~km}$ for its final release. The majority of the complementary dInSAR data points are not more than $5 \mathrm{~km}$ away from grounded areas in Bedmap2. Our interest is not in subkilometre grounding line migration over the observational period but in pinning points away from the main grounded ice body. Therefore we consider points within a certain radius to grounded areas in Bedmap2 as redundant information. Three radii are chosen to remove data points, namely 1 , 5 and $10 \mathrm{~km}$, referred to as PIN1, PIN5 and PIN10 respectively. In order to provide a mask that enters the inversion, the points in the Bedmap2 grid closest to the actual pinning point locations are classified as being grounded. During the inversion, this mask defines extra locations where the basal friction coefficient $\beta^{2}$ is optimised though the Bedmap2 geometry indicates flotation. It is important to not account for these locations in the regularisation $\left(J_{\beta^{2}}^{\text {reg }}\right.$ in Eq. 3) because they introduce large spatial differences. 
Introducing ice rises in this way, the bulk velocity RMS deviation on the ice shelves is not necessarily improved (Table 1). It depends on the selected radius and only PIN5 shows a clear global and shelf-to-shelf improvement. Introducing friction on many shelf locations just a few kilometres downstream of the Bedmap2 grounding line (PIN1) is not conducive to the overall RMS performance of the inversion, as many of these points are potential artefacts from the interpolated Bedmap2 geometry (Fretwell et al., 2013). PIN5 is largely free of such erratic friction points as most pinning points lie far out on the ice shelves.

On individual ice shelves clear improvements are observed. The RMS deviation on the TWG Ice Shelf is reduced by a factor of $\sim 3$ and a zone of erroneously high viscosities is removed (not shown). In fact, the introduction of friction beneath the ice rise of TWG alters the flow field on the eastern part of the ice shelf significantly (Fig. 5a and b). As ice flow is inhibited, flow lines get more aligned with observations and turn away from the basal obstacle. We conclude that the ice rise in this region has an important influence on the shelf dynamics of the eastern region. Also on LC, the mismatch upstream of BIR is virtually removed (Fig. 3e and f). In addition, the inferred viscosity parameter is regionally lowered and hence more consistent with surrounding ice (Fig. 3b and c). On the Brunt Ice Shelf, a similar improvement in the velocity mismatch is seen upstream of the McDonald Ice Rumples. Though the $B$ field is somewhat lowered, values were and are in a physically reasonable range both when accounting for friction at the ice rumples and when not.

Despite the strong improvement seen in these regions, the inversion is hardly facilitated at many other locations where there is evidence for a pinning point (Fig. 6). One obvious reason for no improvement is that the mismatch was already small before accounting for friction there. This might either indicate a weak basal contact or local overfitting unsuppressed by the chosen regularisation. Moreover, many pinning features have a rather small spatial extent, which is more or less well resolved depending on where the model grid points fall. Another reason is that the inversion might not be sufficiently converged, such that these small-scale features would become relevant in the optimisation.

\subsubsection{Identification of uncharted basal contact}

The aim of this section is to use the velocity mismatch map to identify other potential pinning points. Here, we limit our analysis to pinning points close to the ice-shelf fronts, where our approach tends to produce a characteristic signal in the difference map of modelled and observed velocities. There, the signal is also expected to be most pronounced. In addition to the mismatch information, we verify that observed surface velocities actually decrease gradually towards the respective ice front. The identification is performed manually because there are some features that clearly arise from concatenat-
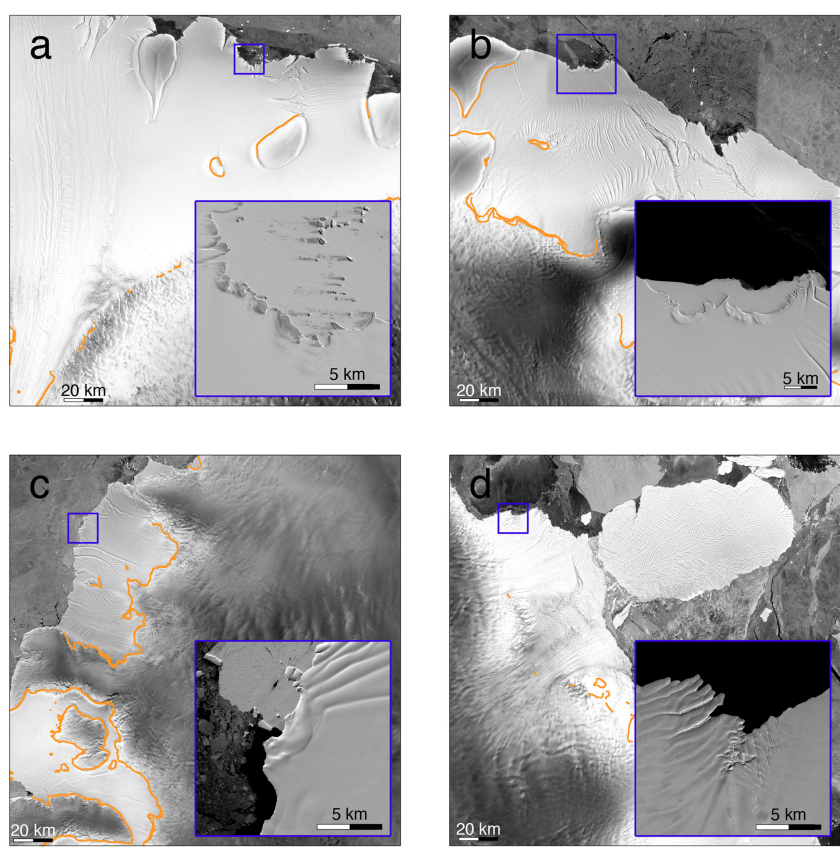

Figure 7. RAMP imagery for Fimbul (a), Mushketov (b), Venable (c) and West Ice Shelf (d). Blue rectangles encircle the locations of the identified PPPs (Table 2). Insets show closeups of these locations with satellite imagery from LIMA. Orange lines delineate multi-year grounding line positions by Rignot et al. (2011a).

ing the velocity mosaic. A good example is Brunt/StancombWills Ice Shelf (Fig. 1), where the mismatch map shows an erratic alternation near the northern shelf front that is traced back to different sensors and acquisition dates. A similar artificial pattern is found close to the front of Ross Ice Shelf, east of Roosevelt Island.

We identify seven locations around Antarctica (Table 2, Figure 6), where there is strong evidence for resistance to the ice-shelf flow and thus for a potential pinning point (PPP). Unfortunately, none of these features is directly crossed by Operation IceBridge flight lines. They are also not found to be consistently attributed to geographic names. The first feature, PPP1, is located at the eastern part of the marine front of Fimbul Ice Shelf (Queen Maud Land), north of Tsiolkovskiy and Kroshka islands (SCAR Gazetteer, US Board on Geographic Names). SCAR Gazetteer actually comprises an ice dome at this location called Avrora Kupol, giving first evidence of a topographic expression of this object. As surface expressions can be detected from satellite imagery, data from the RADARSAT-1 Antarctic Mapping Project (RAMP, Jezek and RAMP Product Team, 2002) and the Landsat Image Mosaic of Antarctica (LIMA, Bindschadler et al., 2008) are consulted (Fig. 7). On Fimbul Ice Shelf, the imagery highlights several surface features where we observe maximum velocity mismatch after the inversion. As these features are close to each other, we cannot discern whether one of them is dominant for the upstream ice-shelf flow. The two PPPs on 
Table 2. Decimal longitudinal and latitudinal range where we find evidence for potential pinning points (PPP). Also given are the respective shelf names. The ice shelf east of Verblyud Island has no name. As its main tributary is Mushketov Glacier, we refer to it as Mushketov Ice Shelf. If a peak in the Bedmap2 surface elevation is discernible, its height is manually estimated with respect to the surrounding shelf surface. If no peak is identifiable, no number is given (“-”).

\begin{tabular}{lllrrll}
\hline & $\begin{array}{l}\text { Northern } \\
\text { boundary }\end{array}$ & $\begin{array}{l}\text { Southern } \\
\text { boundary }\end{array}$ & $\begin{array}{r}\text { Western } \\
\text { boundary }\end{array}$ & $\begin{array}{r}\text { Eastern } \\
\text { boundary }\end{array}$ & $\begin{array}{l}\text { Respective } \\
\text { ice-shelf name }\end{array}$ & $\begin{array}{l}\text { Height of topographic } \\
\text { rise in Bedmap2 }\end{array}$ \\
\hline PPP1 & -70.12 & -70.19 & 2.26 & 2.50 & Fimbul & $\sim 3 \mathrm{~m}$ \\
PPP2 & -69.73 & -69.77 & 17.27 & 17.42 & Mushketov & $\sim 4 \mathrm{~m}$ \\
PPP3 & -69.70 & -69.74 & 17.52 & 17.71 & Mushketov & $\sim 4 \mathrm{~m}$ \\
PPP4 & -67.35 & -67.54 & 81.39 & 81.80 & West & $\sim 15 \mathrm{~m}$ \\
PPP5 & -66.20 & -66.27 & 95.36 & 95.60 & Shackleton & - \\
PPP6 & -75.36 & -75.47 & -145.20 & -144.73 & Nickerson & $\sim 5 \mathrm{~m}$ \\
PPP7 & -72.92 & -72.97 & -86.66 & -86.43 & Venable & $\sim 10 \mathrm{~m}$ \\
\hline
\end{tabular}

Mushketov Ice Shelf are further apart $(\sim 5 \mathrm{~km})$ and are both well imprinted in the velocity mismatch map. On Venable Ice Shelf, the satellite image shows a very gradual imprint of PPP7, while on West Ice Shelf the surface is highly crevassed near PPP4. These differences in the surface expression of pinning points pose a challenge when satellite imagery alone was used for their identification. In fact, the surface elevation product of Bedmap2 already holds a rise of $\sim 3 \mathrm{~m}$ above PPP1 (Table 2). Except for PPP5 on Shackleton Ice Shelf, we confirm similar topographic rises in Bedmap2 at the locations of all the other features.

We find additional confirmation for this interpretation in a recent International Bathymetric Chart of the Southern Ocean (IBCSO: Arndt et al., 2013). It is a comprehensive compilation of bathymetric data around Antarctica. Its subshelf bathymetry is, however, inherited from Bedmap2. On the ocean side of Fimbul Ice Shelf front, the map shows a bathemetric rise just offshore of PPP1 reaching up to $-190 \mathrm{~m}$ below present sea level. The lower surface of the Bedmap2 ice shelf reaches down to $-210 \mathrm{~m}$. Turning to PPP2 and PPP3, the Bedmap2 ocean is very shallow ( $<$ $-100 \mathrm{~m}$ ). The IBCSO bathymetry is significantly deeper there, often by more than $200 \mathrm{~m}$, showing two distinct rises reaching about $-190 \mathrm{~m}$ in close vicinity of PPP3. Also at other PPP locations, IBCSO indicates offshore rises in the bathymetry that are underestimated or ignored in Bedmap2.

\section{Summary and conclusions}

We present a data assimilation approach for the Antarctic ice sheet, inferring two variables simultaneously, namely the basal friction coefficient and the ice viscosity parameter. After convergence, the underlying cost function is reduced by more than 3 orders of magnitude. For the whole of Antarctica, the RMS deviation in the velocity components attains $\pm 9.0 \mathrm{ma}^{-1}$. The match is better on the grounded parts of the ice sheet, while it reaches an average of $\pm 15.2 \mathrm{~m} \mathrm{a}^{-1}$ for all ice shelves. In other studies, similar inversions were conducted to infer the viscosity field of individual shelves (Larour et al., 2005; Borstad et al., 2013; Larour et al., 2014). The general pattern of our inferred viscosity maps agrees well with these regional studies. In addition, the inversion problem is sufficiently conditioned by a dual regularisation and a well-founded initial guess for the two variables. On the ice shelves, the final viscosity map is mostly unaffected by three variants for initialising the parameter field.

As any model application on observed geometries requires an assumption on the ice density, we present several options to guarantee flotation of the shelf geometry in the model. In terms of minimising the velocity RMS deviation, adjusting the ice density to guarantee flotation for the unadjusted Bedmap2 geometry is preferential. However, as a spatially variable density field entails problems in forward modelling, the Bedmap2 thickness field is taken and adjusted to flotation according to model densities for ice and ocean water. If the Bedmap2 geometry is directly taken and not adjusted for flotation, the inferred shelf viscosity is systematically biased. In our case, putting the ice shelves afloat involves a general lowering of the upper surface and, after inversion, less viscous shelf ice.

Remaining velocity differences exhibit uncommonly high magnitudes for the ice shelf of TWG, resulting in a bulk RMS mismatch of $\sim 70 \mathrm{ma}^{-1}$. Large differences are actually limited to the eastern part of this ice shelf, where values typically exceed $100 \mathrm{~m} \mathrm{a}^{-1}$. The differences there arise from an ice rise (Rignot et al., 2014) not included in Bedmap2 and thus unaccounted for in our inversion. As the mismatch is particularly pronounced in this region, this ice rise certainly exerts strong control on the upstream shelf dynamics and, by extension, on the flow of the grounded ice sheet. Therefore, an approach is forwarded that can account for pinning points not present in Bedmap2 during the inversion without adapting the geometry. Applying this approach, the bulk RMS for the TWG Ice Shelf is reduced to $\sim 30 \mathrm{ma}^{-1}$. For other shelves, the improvement is not as expressed but still local mismatches are efficiently removed. Prominent examples are the Bawden Ice Rise on Larsen C and the McDonald Ice Rumples on Brunt 
Ice Shelf. For the whole of Antarctica, the RMS deviation is only moderately reduced to $8.7 \mathrm{ma}^{-1}$ with most improvement on the ice shelves $\left(14.0 \mathrm{ma}^{-1}\right)$.

We are also able to identify a characteristic pattern in the velocity mismatch where the Bedmap2 geometry ignores the presence of pinning points close to the marine shelf front. This information is used in a final step to identify potential pinning points not included in the data sources at hand. We locate seven features around Antarctica that provide prominent flow resistance. Though the identification could be done on the sole basis of the velocities observations or even directly from RADARSAT imagery, our approach implicitly quantifies the effect of these pinning points on ice dynamics. However, our identification does not claim to be complete. It should rather serve to highlight locations relevant for shelf dynamics. Our identification will miss out on ephemeral features that only appear in velocity observations if data acquisition falls into periods of actual ice/bed contact. In addition, our method is less efficient for pinning points away from the ice-shelf front because there ice flow is more likely experiencing multiple sources of resistance that reduce the signal amplitude.

The interpretation of the seven features as pinning points is substantiated by the Bedmap2 surface topography that indicates topographic rises of several metres for six of them. Their surface expressions are also visible in RAMP and LIMA satellite imagery. For further evidence, these features could be delineated by means of dInSAR data (e.g. Rignot et al., 2011a). If the bed contact was confirmed, only direct measurements, either in situ or airborne, could answer to what extent these pinning points pierce the ice body. Yet, such measurements are sparse in Antarctica, meaning that the bathymetry of the ocean cavities beneath the ice shelves is just not known in many places. The Bedmap2 sub-shelf bathymetry is mostly inherited from the original BEDMAP data set (Lythe and Vaughan, 2001) and is based on an simple interpolation between the ice thickness at the grounding line and the seabed near the ice-shelf front. This interpolation regularly spans $100 \mathrm{~km}$. Actual measurements from seismic soundings were limited to Filchner-Ronne, Ross, Amery and the Larsen shelves. For the majority of the ice shelves, this original bathymetry was kept in Bedmap2 but excavated by $20 \mathrm{~m}$ in places where flotation was violated, as suggested by Le Brocq et al. (2010). In the meantime, Operation Ice Bridge collected free-air gravimetry data, primarily in West Antarctica, from which the bathymetry beneath entire shelves was inferred (Tinto and Bell, 2011; Cochran and Bell, 2012). Large areas could be covered with this airborne sensor. As the accuracy of this technique is low for bathymetry (Brisbourne et al., 2014), on-site seismic measurements should complement this data for the most prominent pinning points.

Finally, we want to acknowledge the many years and decades of data acquisition on Antarctica, which are a prerequisite to this study. Data compilation products for ice geometry and ice velocities are now available on comparable resolution (Morlighem et al., 2010; Rignot et al., 2011b; Fretwell et al., 2013), which triggered ice-sheet-wide assimilations necessary to determine poorly constrained parameters in ice flow models (e.g. Gillet-Chaulet et al., 2012; Morlighem et al., 2013; Arthern et al., 2015). The data assimilation presented here has reached a quality such that it can serve to identify inconsistencies in and between the velocity and geometry data sets. As the optimisation primarily addresses velocity differences, our assimilation reveals inhomogeneities in the surface velocity mosaic. However, more importantly it points towards regions where observed ice flow is not reconcilable with the geometric database. This is especially the case for pinning points which can alter the dynamics of a larger area. Consequently, ice flow models require the location and extent of these pinning areas as input in order to be able to reproduce observed velocities. Only then could realistic stress distributions be inferred, which would make it possible to quantify the resistance that ice shelves exert on the upstream flow. For reliable model projections of pinned ice shelves and their upstream tributaries, the exact bathymetry of the bed contact is a prerequisite, as it determines the timing of a potential future ungrounding. This is exemplified by the TWG setup. Despite our good knowledge on the spatial extent of this ice rise (Rignot, 2001; Rignot et al., 2014), we have hardly any information on how much it actually protrudes the ice shelf. For now, any approach to model its future response is controversial to say the least. Once the shelves become ungrounded, we expect a significant acceleration reaching up to the grounded ice sheet and, consequently, a retreat of the grounding line (Favier et al., 2012). For TWG and many other glaciers in the ASS, grounding lines often retreated (Park et al., 2013; Rignot et al., 2014) into deeper bathymetry, which facilitates increasing ice export over the grounding line (e.g. Schoof, 2007). This provides a positive feedback on further acceleration and retreat, often associated with an inherent instability of the entire West Antarctic ice sheet (Bamber et al., 2009; Joughin et al., 2014). In this light, we want to put forward an appeal for a coordinated effort to produce a contemporaneous high-resolution data set for ice geometry, ice dynamics and sub-shelf bathymetry in this region. Additionally, observations on the exact geometry of the pinning points, which are not in Bedmap2, are highly anticipated by the model community, because these features can affect the dynamics of entire ice shelves. Priority should be given to the pinning points that give rise to a large velocity mismatch when not accounted for in the presented data assimilation.

Acknowledgements. This study was funded by the French National Research Agency (ANR) under the SUMER (Blanc SIMI 6) 2012 project referenced as ANR-12-BS06-0018. Results presented in this publications are based on numerical simulation performed on two platforms for scientific computing. Part of the simulations were conducted using the Froggy platform of the CIMENT (Calcul In- 
tensif/Modélisation/Expérimentation Numérique et Technologique) infrastructure, which is supported by the Rhône-Alpes region (grant CPER07,3 CIRA), the OSUG@2020 labex (reference ANR10 LABX56) and the Equip@ Meso project (reference ANR10-EQPX-29-01) of the programme Investissements d'Avenir supervised by the Agence Nationale pour la Recherche. The other part of the simulations were conducted at the CINES (Centre Informatique National de l'Enseignement Supérieur) computing centre under allocation 2015-016066 from GENCI (Grand Equipement National de Calcul Intensif). Results presented here also received support and benefited from the development team at the CSC-IT Center for Science Ltd. (Finland).

Edited by: G. H. Gudmundsson

\section{References}

Armstrong, T., Roberts, B., and Swithinbank, C.: Proposed new terms and definitions for snow and ice features, Polar Rec., 18, 501-502, 1977

Arndt, J., Schenke, H., Jakobsson, M., Nitsche, F., Buys, G., Goleby, B., Rebesco, M., Bohoyo, F., Hong, J., Black, J., Greku, R., Udintsev, G., Barrios, F., Reynoso-Peralta, W., Taisei, M., and Wigley, R.: The International Bathymetric Chart of the Southern Ocean (IBCSO) version 1.0: a new bathymetric compilation covering circum-Antarctic waters, Geophys. Res. Lett., 40, 31113117, doi:10.1002/grl.50413, 2013.

Arthern, R. and Gudmundsson, G.: Initialization of ice-sheet forecasts viewed as an inverse Robin problem, J. Glaciol., 56, 527533, doi:10.3189/002214310792447699, 2010.

Arthern, R. J., Hindmarsh, R. C. A., and Wilams, C. R.: Initialization of ice-sheet forecasts viewed as an inverse Robin problem, J. Geophys. Res., doi:10.1002/2014JF003239, online first, 2015.

Bamber, J., Riva, R., Vermeersen, B., and LeBrocq, A.: Reassessment of the potential sea-level rise from a collapse of the West Antarctic Ice Sheet, Science, 324, 901-903, doi:10.1126/science.1169335, 2009.

Berthier, E., Scambos, T., and Shuman, C.: Mass loss of Larsen B tributary glaciers (Antarctic Peninsula) unabated since 2002, Geophys. Res. Lett., 39, L13501, doi:10.1029/2012GL051755, 2012.

Bindschadler, R., Vornberger, P., Fleming, A., Fox, A., Mullins, J., Binnie, D., Paulsen, S., Granneman, B., and Gorodetzky, D.: The Landsat image mosaic of Antarctica, Remote Sens. Environ., 112, 4214-4226, doi:10.1016/j.rse.2008.07.006, 2008.

Borstad, C. P., Rignot, E., Mouginot, J., and Schodlok, M. P.: Creep deformation and buttressing capacity of damaged ice shelves: theory and application to Larsen $\mathrm{C}$ ice shelf, The Cryosphere, 7, 1931-1947, doi:10.5194/tc-7-1931-2013, 2013.

Brisbourne, A. M., Smith, A. M., King, E. C., Nicholls, K. W., Holland, P. R., and Makinson, K.: Seabed topography beneath Larsen C Ice Shelf from seismic soundings, The Cryosphere, 8, 1-13, doi:10.5194/tc-8-1-2014, 2014.

Cochran, J. and Bell, R.: Inversion of IceBridge gravity data for continental shelf bathymetry beneath the Larsen Ice Shelf, Antarctica, J. Glaciol., 58, 540-552, doi:10.3189/2012JoG11J033, 2012.
Craven, M., Allison, I., Fricker, H., and Warner, R.: Properties of a marine ice layer under the Amery Ice Shelf, East Antarctica, J. Glaciol., 55, 717-728, 2009.

Depoorter, M., Bamber, J., Griggs, J., Lenaerts, J., Ligtenberg, S., van den Broeke, M., and Moholdt, G.: Calving fluxes and basal melt rates of Antarctic ice shelves, Nature, 502, 89-93, doi:10.1038/nature12567, 2013.

Favier, L., Gagliardini, O., Durand, G., and Zwinger, T.: A threedimensional full Stokes model of the grounding line dynamics: effect of a pinning point beneath the ice shelf, The Cryosphere, 6, 101-112, doi:10.5194/tc-6-101-2012, 2012.

Fretwell, P., Pritchard, H. D., Vaughan, D. G., Bamber, J. L., Barrand, N. E., Bell, R., Bianchi, C., Bingham, R. G., Blankenship, D. D., Casassa, G., Catania, G., Callens, D., Conway, H., Cook, A. J., Corr, H. F. J., Damaske, D., Damm, V., Ferraccioli, F., Forsberg, R., Fujita, S., Gim, Y., Gogineni, P., Griggs, J. A., Hindmarsh, R. C. A., Holmlund, P., Holt, J. W., Jacobel, R. W., Jenkins, A., Jokat, W., Jordan, T., King, E. C., Kohler, J., Krabill, W., Riger-Kusk, M., Langley, K. A., Leitchenkov, G., Leuschen, C., Luyendyk, B. P., Matsuoka, K., Mouginot, J., Nitsche, F. O., Nogi, Y., Nost, O. A., Popov, S. V., Rignot, E., Rippin, D. M., Rivera, A., Roberts, J., Ross, N., Siegert, M. J., Smith, A. M., Steinhage, D., Studinger, M., Sun, B., Tinto, B. K., Welch, B. C., Wilson, D., Young, D. A., Xiangbin, C., and Zirizzotti, A.: Bedmap2: improved ice bed, surface and thickness datasets for Antarctica, The Cryosphere, 7, 375-393, doi:10.5194/tc-7-3752013, 2013.

Gagliardini, O. and Zwinger, T.: The ISMIP-HOM benchmark experiments performed using the Finite-Element code Elmer, The Cryosphere, 2, 67-76, doi:10.5194/tc-2-67-2008, 2008.

Gagliardini, O., Zwinger, T., Gillet-Chaulet, F., Durand, G., Favier, L., de Fleurian, B., Greve, R., Malinen, M., Martín, C., Råback, P., Ruokolainen, J., Sacchettini, M., Schäfer, M., Seddik, H., and Thies, J.: Capabilities and performance of Elmer/Ice, a newgeneration ice sheet model, Geosci. Model Dev., 6, 1299-1318, doi:10.5194/gmd-6-1299-2013, 2013.

Gillet-Chaulet, F., Gagliardini, O., Seddik, H., Nodet, M., Durand, G., Ritz, C., Zwinger, T., Greve, R., and Vaughan, D. G.: Greenland ice sheet contribution to sea-level rise from a newgeneration ice-sheet model, The Cryosphere, 6, 1561-1576, doi:10.5194/tc-6-1561-2012, 2012.

Griggs, J. and Bamber, J.: Antarctic ice-shelf thickness from satellite radar altimetry, J. Glaciol., 57, 485-498, doi:10.3189/002214311796905659, 2011

Gudmundsson, G. H.: Ice-shelf buttressing and the stability of marine ice sheets, The Cryosphere, 7, 647-655, doi:10.5194/tc-7647-2013, 2013.

Hansen, P.: Analysis of discrete ill-posed problems by means of the L-curve, SIAM Rev., 34, 561-580, doi:10.1137/1034115, 1992.

Hindmarsh, R.: The role of membrane-like stresses in determining the stability and sensitivity of the Antarctic ice sheets: back pressure and grounding line motion, Philos. T. R. Soc. A, 364, 1733 1767, doi:10.1098/rsta.2006.1797, 2006.

Holt, J., Blankenship, D., Morse, D., Young, D., Peters, M., Kempf, S., Richter, T., Vaughan, D., and Corr, H.: New boundary conditions for the West Antarctic Ice Sheet: subglacial topography of the Thwaites and Smith glacier catchments, Geophys. Res. Lett., 33, L09502, doi:10.1029/2005GL025561, 2006. 
Jansen, D., Kulessa, B., Sammonds, P., Luckman, A., King, E., and Glasser, N.: Present stability of the Larsen C Ice Shelf, Antarctic Peninsula, J. Glaciol., 56, 593-600, doi:10.3189/002214310793146223, 2010.

Jay-Allemand, M., Gillet-Chaulet, F., Gagliardini, O., and Nodet, M.: Investigating changes in basal conditions of Variegated Glacier prior to and during its 1982-1983 surge, The Cryosphere, 5, 659-672, doi:10.5194/tc-5-659-2011, 2011.

Jezek, K. and RAMP Product Team: RAMP AMM-1 SAR Image Mosaic of Antarctica. Version 2, Alaska Satellite Facility, in association with the National Snow and Ice Data Center, Boulder, CO, USA, 2002.

Joughin, I.: Ice-sheet velocity mapping: a combined interferometric and speckle-tracking approach, Ann. Glaciol., 34, 195-201, doi:10.3189/172756402781817978, 2002.

Joughin, I., Smith, B., and Holland, D.: Sensitivity of 21st century sea level to ocean-induced thinning of Pine Island Glacier, Antarctica, Geophys. Res. Lett., 37, L20502, doi:10.1029/2010GL044819, 2010.

Joughin, I., Smith, B., and Medley, B.: Marine ice sheet collapse potentially under way for the Thwaites Glacier Basin, West Antarctica, Science, 344, 735-738, doi:10.1126/science.1249055, 2014.

Khazendar, A., Rignot, E., and Larour, E.: Larsen B Ice Shelf rheology preceding its disintegration inferred by a control method, Geophys. Res. Lett., 34, L19503, doi:10.1029/2007GL030980, 2007.

Khazendar, A., Rignot, E., and Larour, E.: Roles of marine ice, rheology, and fracture in the flow and stability of the Brunt/Stancomb-Wills Ice Shelf, J. Geophys. Res., 114, F04007, doi:10.1029/2008JF001124, 2009.

Khazendar, A., Rignot, E., and Larour, E.: Acceleration and spatial rheology of Larsen C Ice Shelf, Antarctic Peninsula, Geophys. Res. Lett., 38, L09502, doi:10.1029/2011GL046775, 2011.

Kulessa, B., Jansen, D., Luckman, A., King, E., and Sammonds, P.: Marine ice regulates the future stability of a large Antarctic ice shelf, Nature Communications, 5, 3707, doi:10.1038/ncomms4707, 2014.

Larour, E., Rignot, E., Joughin, I., and Aubry, D.: Rheology of the Ronne Ice Shelf, Antarctica, inferred from satellite radar interferometry data using an inverse control method, Geophys. Res. Lett., 32, L05503, doi:10.1029/2004GL021693, 2005.

Larour, E., Khazendar, A., Borstad, C., Seroussi, H., Morlighem, M., and Rignot, E.: Representation of sharp rifts and faults mechanics in modeling ice shelf flow dynamics: application to Brunt/Stancomb-Wills Ice Shelf, Antarctica, J. Geophys. Res., 119, 1918-1935, doi:10.1002/2014JF003157, 2014.

Le Brocq, A. M., Payne, A. J., and Vieli, A.: An improved Antarctic dataset for high resolution numerical ice sheet models (ALBMAP v1), Earth Syst. Sci. Data, 2, 247-260, doi:10.5194/essd-2-247-2010, 2010.

Lythe, M. B. and Vaughan, D. G.: BEDMAP: a new ice thickness and subglacial topographic model of Antarctica, J. Geophys. Res., 106, 11335-11351, doi:10.1029/2000JB900449, 2001.

MacAyeal, D.: Large-scale ice flow over a viscous basal sediment: theory and application to ice stream B, Antarctica, J. Geophys. Res., 94, 4071-4087, doi:10.1029/JB094iB04p04071, 1989.

MacAyeal, D.: A tutorial on the use of control methods in ice sheet modelling, J. Glaciol., 39, 91-98, 1993.
MacAyeal, D., Scambos, T. A., Hulbe, C. L., and Fahnestock, M. A.: Catastrophic ice-shelf break-up by an iceshelf-fragment-capsize mechanism, J. Glaciol., 49, 22-36, doi:10.3189/172756503781830863, 2003.

Morlighem, M., Rignot, E., Seroussi, H., Larour, E., Ben Dhia, H., and Aubry, D.: Spatial patterns of basal drag inferred using control methods from a full-Stokes and simpler models for Pine Island Glacier, West Antarctica, Geophys. Res. Lett., 37, L14502, doi:10.1029/2010GL043853, 2010.

Morlighem, M., Seroussi, H., Larour, E., and Rignot, E.: Inversion of basal friction in Antarctica using exact and incomplete adjoints of a higher-order model, J. Geophys. Res., 118, 17461753, doi:10.1002/jgrf.20125, 2013.

Park, J. W., Gourmelen, N., Shepherd, A., Kim, S. W., Vaughan, D. G., and Wingham, D. J.: Sustained retreat of the Pine Island Glacier, Geophys. Res. Lett., 40, 2137-2142, doi:10.1002/grl.50379, 2013.

Paterson, W.: The Physics of Glaciers, Pergamon, Oxford, UK, 1994.

Pattyn, F.: Antarctic subglacial conditions inferred from a hybrid ice sheet/ice stream model, Earth Planet. Sc. Lett., 295, 451-461, doi:10.1016/j.eps1.2010.04.025, 2010.

Pritchard, H., Arthern, R., Vaughan, D., and Edwards, L.: Extensive dynamic thinning on the margins of the Greenland and Antarctic ice sheets, Nature, 461, 971-975, doi:10.1038/nature08471, 2009.

Pritchard, H., Ligtenberg, S., Fricker, H., Vaughan, D., van den Broeke, M., and Padman, L.: Antarctic ice-sheet loss driven by basal melting of ice shelves, Nature, 484, 502-505, doi:10.1038/nature10968, 2012.

Rignot, E.: Evidence for rapid retreat and mass loss of Thwaites Glacier, West Antarctica, J. Glaciol., 47, 213-222, doi:10.3189/172756501781832340, 2001.

Rignot, E., Bamber, J., van den Broeke, M., Davis, C., Li, Y., van de Berg, W., and van Meijgaard, E.: Recent Antarctic ice mass loss from radar interferometry and regional climate modelling, Nat. Geosci., 1, 106-110, doi:10.1038/ngeo102, 2008.

Rignot, E., Mouginot, J., and Scheuchl, B.: Antarctic grounding line mapping from differential satellite radar interferometry, Geophys. Res. Lett., 38, L10504, doi:10.1029/2011GL047109, 2011a.

Rignot, E., Mouginot, J., and Scheuchl, B.: Ice flow of the Antarctic Ice Sheet, Science, 333, 1427-1430, doi:10.1126/science.1208336, 2011b.

Rignot, E., Jacobs, S., Mouginot, J., and Scheuchl, B.: Iceshelf melting around Antarctica, Science, 341, 266-270, doi:10.1126/science.1235798, 2013.

Rignot, E., Mouginot, J., Morlighem, M., Seroussi, H., and Scheuchl, B.: Widespread, rapid grounding line retreat of Pine Island, Thwaites, Smith, and Kohler glaciers, West Antarctica, from 1992 to 2011, Geophys. Res. Lett., 41, 3502-3509, doi:10.1002/2014GL060140, 2014.

Rott, H., Müller, F., Nagler, T., and Floricioiu, D.: The imbalance of glaciers after disintegration of Larsen-B ice shelf, Antarctic Peninsula, The Cryosphere, 5, 125-134, doi:10.5194/tc-5-1252011, 2011.

Scambos, T., Bohlander, J., Shuman, C., and Skvarca, P.: Glacier acceleration and thinning after ice shelf collapse in the Larsen 
B embayment, Antarctica, Geophys. Res. Lett., 31, L18402, doi:10.1029/2004GL020670, 2004.

Schoof, C.: Ice sheet grounding line dynamics: steady states, stability, and hysteresis, J. Geophys. Res., 112, F03S28, doi:10.1029/2006JF000664, 2007.

Shepherd, A., Ivins, E., Geruo, A., Barletta, V., Bentley, M., Bettadpur, S., Briggs, K., Bromwich, D., Forsberg, R., Galin, N., Horwath, M., Jacobs, S., Joughin, I., King, M., Lenaerts, J., Li, J., Ligtenberg, S., Luckman, A., Luthcke, S., McMillan, M., Meister, R., Milne, G., Mouginot, J., Muir, A., Nicolas, J., Paden, J., Payne, A., Pritchard, H., Rignot, E., Rott, H., Sørensen, L., Scambos, T., Scheuchl, B., Schrama, E., Smith, B., Sundal, A., van Angelen, J., van de Berg, W., van den Broeke, M., Vaughan, D., Velicogna, I., Wahr, J., Whitehouse, P., Wingham, D., Yi, D., Young, D., and Zwally, H.: A reconciled estimate of ice-sheet mass balance, Science, 338, 11831189, doi:10.1126/science.1228102, 2012.

Thomas, R.: Ice shelves: a review, J. Glaciol., 24, 273-286, 1979.

Tinto, K. and Bell, R.: Progressive unpinning of Thwaites Glacier from newly identified offshore ridge: constraints from aerogravity, Geophys. Res. Lett., 38, L20503, doi:10.1029/2011GL049026, 2011. van den Broeke, M.: Depth and Density of the Antarctic Firn Layer, Arct. Antarct. Alp. Res., 40, 432-438, doi:10.1657/15230430(07-021)[BROEKE]2.0.CO;2, 2008.

Van Der Veen, C.: Fundamentals of Glacier Dynamics, Taylor \& Francis, Rotterdam, the Netherlands, 1999.

Van Liefferinge, B. and Pattyn, F.: Using ice-flow models to evaluate potential sites of million year-old ice in Antarctica, Clim. Past, 9, 2335-2345, doi:10.5194/cp-9-2335-2013, 2013.

Vaughan, D., Corr, H., Ferraccioli, F., Frearson, N., O'Hare, A., Mach, D., Holt, J., Blankenship, D., Morse, D., and Young, D.: New boundary conditions for the West Antarctic ice sheet: subglacial topography beneath Pine Island Glacier, Geophys. Res. Lett., 33, L09501, doi:10.1029/2005GL025588, 2006.

Vieli, A., Payne, A., Du, Z., and Shepherd, A.: Numerical modelling and data assimilation of the Larsen B ice shelf, Antarctic Peninsula, Philos. T. R. Soc. A, 364, 1815-1839, doi:10.1098/rsta.2006.1800, 2006.

Vieli, A., Payne, A., Shepherd, A., and Du, Z.: Causes of precollapse changes of the Larsen B Ice Shelf: numerical modelling and assimilation of satellite observations, Earth Planet. Sc. Lett., 259, 297-306, doi:10.1016/j.eps1.2007.04.050, 2007. 